\title{
Gradation of unstable angina based on a sensitive immunoassay for serum creatine kinase $\mathrm{MB}$
}

Hans Erik Bøtker, Jan Ravkilde, Peter Søgaard, Poul Jørgen Jørgensen, Mogens Hørder, Kristian Thygesen

\begin{abstract}
A newly developed, highly sensitive immunoassay for creatine kinase MB isoenzyme was evaluated in 68 patients with or without different types of ischaemic heart disease. Patients were classified on the basis of clinical criteria in four groups: no ischaemic heart disease, stable angina, unstable angina, and acute myocardial infarction. Enzyme concentration in patients with stable angina was the same (even during exercise) as seen in the patients without ischaemic heart disease. Patients with unstable angina, however, could be divided into two groups. One group showed clear evidence of severe myocardial ischaemia by serial changes and higher mean values of creatine kinase MB up to 40 hours after the onset of symptoms, whereas in the remainder values were stable and resembled those seen in the patients without ischaemic heart disease. The changes in concentration correlated with signs of repetitive ischaemic episodes deduced from continuous ST segment monitoring during the first 24 hours after admission. These findings indicate that patients with unstable angina are a heterogenous group. In some, severe and prolonged ischaemia can be detected by a serological assay with high sensitivity.
\end{abstract}

Ischaemic heart disease is expressed clinically as stable chronic angina and the acute ischaemic syndromes of unstable angina, acute myocardial infarction, and sudden ischaemic death. Sound clinical and pathological evidence indicates an underlying pathogenesis of chronic static lesions or an acute and evolving process superimposed on atherosclerosis. ${ }^{1-4}$ The mechanism that leads to acute ischaemia is uncertain. Thrombosis is a major factor, ${ }^{1-4}$ but progression of atherosclerosis and coronary spasm may also be important. ${ }^{45}$ These conditions can cause myocardial ischaemia, which in cases of myocardial infarction results in cell death and tissue necrosis. In unstable angina, a dynamic stenosis can also cause unpredictable episodes of ischaemia. Such attacks of repeated ischaemia are not detectable by conventional methods such as electrocardiography and immunochemical, chromatographic, or electrophoretic assays for serum creatine kinase isoenzymes, but some studies suggest that they cause a slight release of enzymes. ${ }^{67}$
We evaluated a newly developed, highly sensitive immunoassay for the creatine kinase isoenzyme $\mathrm{MB}$ in patients with ischaemic heart disease, with a view to classifying their disease on the basis of biochemical evidence of slight myocardial damage.

\section{Patients and methods}

PATIENTS

The study population consisted of 68 patients divided into four groups: 23 patients without ischaemic heart disease (group 1); 10 patients with stable angina pectoris (group 2); 21 patients with unstable angina (group 3); and 14 patients with acute myocardial infarction (group 4). The patients without ischaemic heart disease and patients with stable angina attended our outpatient clinic. Patients with stable angina were taking antianginal agents (long acting nitrates, calcium antagonists, or $\beta$ blockers, or a combination of these drugs). Patients with unstable angina and acute myocardial infarction were recruited after admission to the coronary care unit within 12 hours of the development of retrosternal pain at rest. The mean time from onset of chest pain was $4 \mathrm{~h} 10 \mathrm{~min}$ (range $55 \mathrm{~min}-10 \mathrm{~h} 30 \mathrm{~min}$ ) in patients with unstable angina and $3 \mathrm{~h} 35 \mathrm{~min}$ (range $1 \mathrm{~h}-10 \mathrm{~h} 30 \mathrm{~min}$ ) in patients with acute myocardial infarction.

Eight $(38 \cdot 1 \%)$ of the 21 patients with unstable angina had not previously had symptoms of ischaemic heart disease. Thirteen patients $(61.9 \%)$ had well established ischaemic heart disease-chronic stable angina in $12(57 \cdot 1 \%)$ and/or previous myocardial infarction in nine $(42.9 \%)$. Among these, five patients were treated with nitrates, one with a $\beta$ blocker agent, three with calcium antagonists, and two with a combination of $\beta$ blockers and calcium antagonists.

Six $(46.2 \%)$ of the patients with acute myocardial infarction had previously had symptoms of ischaemic heart disease: five had had chronic stable angina and four an earlier myocardial infarct. One patient was treated with nitrates, two patients with calcium antagonists, and two patients with $\beta$ blockers.

Patients admitted to hospital with unstable angina and acute myocardial infarction were treated with bed rest and control of cardiac pain by nitrates, morphine, and oxygen. No patient had haemodynamic disturbances or arrhythmias that required medical treatment. During the period of blood sampling aspirin treatment was started in all patients. Four patients with acute myocardial infarction started taking diltiazem and five others were 
treated with intravenous glyceryl trinitrate. All the patients with unstable angina were treated with diltiazem and seven were given intravenous glyceryl trinitrate. A maximum of $480 \mathrm{ml}$ of glyceryl trinitrate was infused in 24 hours. Treatment did not influence the interpretation of the analytical results because in each patient the concentration of serum albumin remained constant within the study period.

Informed consent was obtained from each patient and the study was approved by the regional scientific ethics committee.

\section{DIAGNOSTIC CRITERIA}

Group 1 (no ischaemia) comprised patients without a history of chest pain and without electrocardiographic signs of ischaemia both at rest and during exercise. Patients in group 2 (stable angina) had typical attacks of chest pain provoked by physical exertion or psychological factors that were relieved by glyceryl trinitrate. The diagnosis was confirmed by a positive exercise test during which chest pain was provoked along with at least $0.1 \mathrm{mV} \mathrm{ST} \mathrm{depression.} \mathrm{Unstable} \mathrm{angina}$ (group 3) was diagnosed on the basis of chest pain at rest or brought on by minimal exertion and/or an entirely new pattern of chest pain in patients previously classified as having chronic angina. ${ }^{8} \mathrm{ST}$ depression or $\mathrm{T}$ wave inversion were not obligatory; none had signs of myocardial infarction. Conventional serum creatine kinase $B$ residual activity (that is after removal of $M M$ and part of $M B$ ) was within normal range $(<12 \mathrm{U} / \mathrm{l})$ throughout the period of measurement. The diagnosis of acute myocardial infarction was based on the criteria of the World Health Organisation that is, characteristic chest pain, unequivocal signs of infarction in the electrocardiogram, and a characteristic increase in enzyme activity of serum creatine kinase $B$ and lactate dehydrogenase.

\section{PROCEDURE}

After informed consent was obtained, long acting antianginal medication was stopped a week before the study in the patients with stable angina. The patients without ischaemic disease and with stable angina were exercised on bicycles-until exhaustion in patients without ischaemia and until both pain and ST depression of at least $0.1 \mathrm{mV}$ occurred in patients with stable angina. Blood samples were drawn before and every 3-6 hours up to 24 hours after exercise. Blood samples were drawn from patients with acute myocardial infarction and unstable angina on admission and every 3-6 hours during the first 24 hours and then every eight hours up to 72 hours.

\section{BLOOD SAMPLING}

Samples were drawn into tubes without anticoagulant through a catheter permanently placed in an antecubital vein. The samples were stored at $+4 \mathrm{C}$ for 15 minutes and then centrifuged at $3000 \mathrm{~g}$ for 10 minutes. The serum was stored at $-21 \mathrm{C}$ until analysis.
After thawing the serum was again centrifuged to remove any precipitate.

\section{ANALYTICAL METHODS}

The creatine kinase (EC 2.7.3.2) isoenzyme $\mathrm{MB}$ was measured by a newly developed and specially designed highly sensitive enzyme labelled immunosorbent assay (NovoClone CK-MB, Novo Biolabs, Cambridge, United Kingdom). Serum samples were simultaneously incubated with CK-B-specific antibodies attached to the polystyrene surface of the wells in a microtitration plate and with CK-M-specific antibodies conjugated with peroxidase. After one hour's incubation the microtitration plate was washed to remove non-adherent components and the remaining peroxidase activity was measured by an end point assay with orthophenyl diamine as the substrate. The incubation time was 15 minutes and the absorbance was read on an Archimedes plate reader (Novo, Copenhagen). We established a calibration curve using samples with concentrations of 1$30 \mu \mathrm{g} / 1$. All controls, calibration samples, and clinical samples were analysed in quadruplicate and the figures averaged to minimise variability. Specimens containing more than $30 \mu \mathrm{g}$ of creatine kinase MB per litre were reassayed by the same assay with a wider range of detectability.

In a previous study of 315 outpatients (132 men and 183 women) without myocardial diseases the reference interval was $0-6 \mu \mathrm{g} / 1$. The overall median of the log gaussian distribution was $1.91 \mu \mathrm{g} / 1(2.03 \mu \mathrm{g} / \mathrm{l}$ for men and $1.79 \mu \mathrm{g} / 1$ for women). Total and within assay coefficient of variance was less than $6 \%$ at the upper reference limit. The detection limit was $0 \cdot 1$ $\mu \mathrm{g} / 1^{10}$

The serum concentration of the creatine kinase B subunit was measured by an homogeneous enzyme immunoassay after inhibition of creatine kinase M-subunit activity. ${ }^{11}$ Correction for residual adenylate kinase was done before we calculated the enzyme concentrations. For a creatine kinase B-subunit activity of $20 \mathrm{U} / 1$ the coefficient of variance was $5 \%$.

\section{HOLTER MONITORING}

The ST segment was monitored in patients admitted to the coronary care unit with angina at rest. Recordings were taken from an anterior lead (CM5) and an inferior lead on magnetic tapes (Tracker recorder, Reynolds Medical, England). Tapes from patients with unstable angina were analysed for ST segment changes at Reynolds Medical by computer. Significant ST segment depression was defined as a horizontal or downward sloping ST segment shift of $>0.1 \mathrm{mV} 0.08 \mathrm{~s}$ after the $\mathrm{J}$ point that persisted for more than 1 minute.

\section{STATISTICAL ANALYSIS}

We used Student's $t$ test to analyse the significance of difference between means and the $F$ statistic for the significance between the variances. We used Fisher's exact test to measure the significance of association be- 
Figure 1 Serum creatine kinase $M B$ concentration (mean ( $S E M)$ ) in four patient groups measured at three hour intervals in the first 24 hours after exercise no ischaemic heart disease $(\triangle)$ and stable angina ( $)$ ) and at 3-8 hour intervals in the 72 hours from onset of chest pain (unstable angina (O) and acute myocardial infarction ( $)$ )

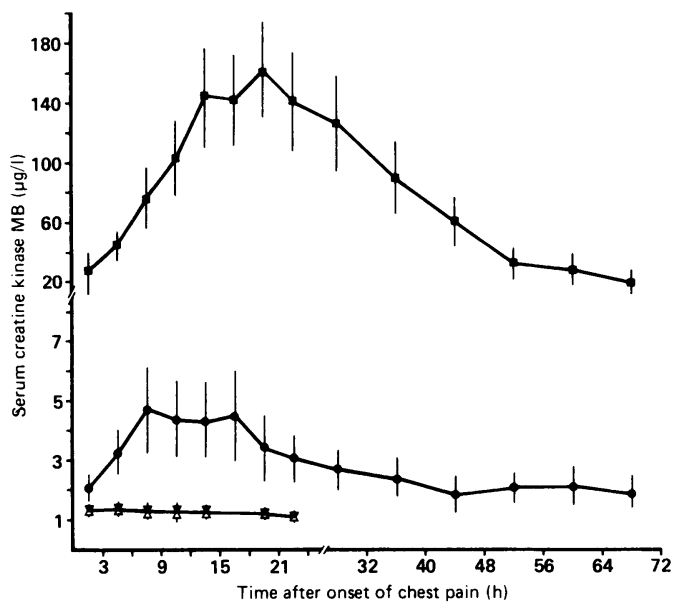

tween serum enzyme fluctuation and Holter analysis. p Values of $<0.05$ were regarded as significant.

\section{Results}

PATTERNS OF CREATINE KINASE MB

Figure 1 shows the mean values of serum creatine kinase $\mathrm{MB}$ concentration every three hours during the first 24 hours after exercise in the patients without ischaemic disease and in those with stable angina and during the first 72 hours after the onset of chest pain in patients with unstable angina or acute myocardial infarction. Because there was no difference between the mean concentrations of serum creatine kinase $\mathrm{MB}$ in patients without ischaemic heart disease and patients with stable angina we considered groups 1 and 2 together. The patients (group 3) with unstable angina had a higher mean concentration than this combination group from 3-6 hours to 21-24 hours $(\mathrm{p}<0.05)$. Patients with acute myocardial infarction had significantly higher creatine kinase $\mathrm{MB}$ concentration than those with unstable angina from 3-6 hours to 64-72 hours $(\mathrm{p}<0.01)$.

To determine whether enzyme release occurs during exercise, serum concentrations of creatine kinase MB were measured before, immediately after, and one hour after an exercise test in patients without ischaemic heart disease and patients with stable angina. These

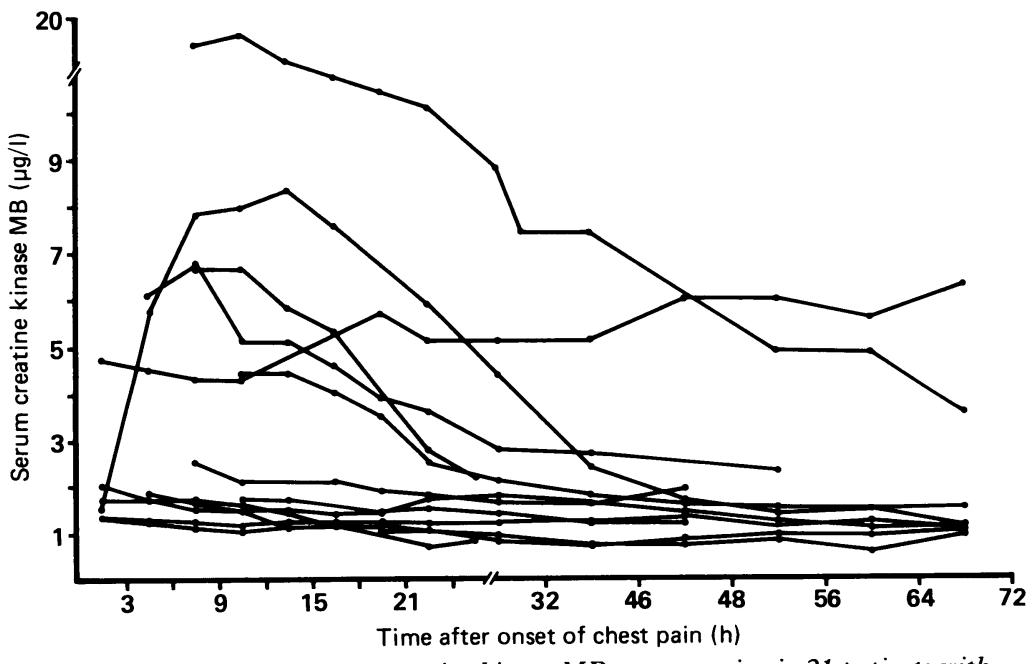

Figure 2 Time course of serum creatine kinase $M B$ concentration in 21 patients with unstable angina measured at 3-8 hour intervals for 72 hours after onset of chest pain.

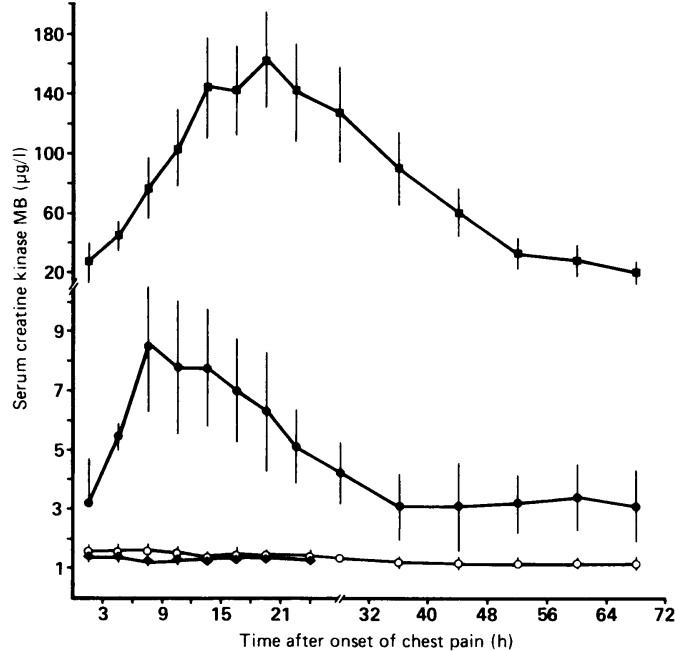

Figure 3 Serum creatine kinase $M B$ concentration (mean (SEM)) in $U A(-)(O)$ and $U A(+)(0)$ patients measured every 3-8 hours in the 72 hours after the onset of chest pain compared with mean concentration in the combined groups of patients without ischaemic hear disease or with stable angina ( ) and patients with acute myocardial infarction ( $)$.

concentrations resembled those measured 3-24 hours after exercise.

VARIABILITY OF SERUM CREATINE KINASE MB There was considerable variation in the patients with acute myocardial infarction and in eight $(38 \%)$ of the patients with unstable angina (fig 2). In the group with unstable angina $13(62 \%)$ patients had almost constant values $(p<0.01)$. The time course of changing enzyme concentrations in seven of the eight patients with enzyme fluctuation was similar to the curves obtained from patients with acute myocardial infarction. One patient had a different time course because the serum concentration of creatine kinase $\mathrm{MB}$ increased somewhat throughout the period of investigation. This patient had prolonged periods of chest pain, but did otherwise not differ from the others.

In figure 3 the mean concentrations of serum creatine kinase $\mathrm{MB}$ in the eight patients with unstable angina and enzyme changes $\mathrm{UA}(+)$ and the 13 patients with unstable angina and no enzyme changes $\mathrm{UA}(-)$ are compared with concentrations in the combined group (no ischaemic heart disease + stable angina) and the group with acute myocardial infarction. The UA(+) group had significantly higher mean values than the combined group in the interval from 3-6 hours to 32-40 hours ( $p<$ $0 \cdot 05)$. The UA (-) group did not differ from the combined group. The UAP $(+)$ group had a creatine kinase MB concentration curve that resembled that of the patients with acute myocardial infarction but the concentration was significantly lower in the interval from 3-6 hours to $32-40$ hours $(p<0.05)$. There was an earlier peak of serum creatine kinase $M B$ in the $\mathrm{UA}(+)$ group than in the patients with acute myocardial infarction.

COMPARISON WITH CREATINE KINASE-B

Figure 4 shows that the mean serum creatine kinase-B residual activity was similar in the UA $(+)$ and UA $(-)$ patients. 


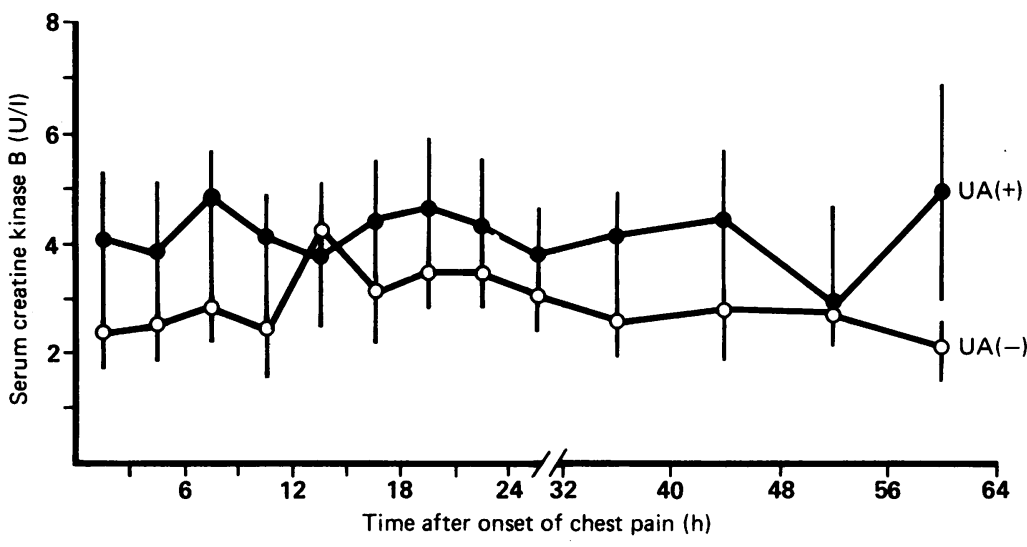

Figure 4 Serum creatine kinase $B$ residual activity (mean (SEM)) in $U A(-)$ and $U A(+)$ groups measured every 3-8 hours in the 72 hours after the onset of chest pain.

CREATINE KINASE MB AND ELECTROCARDIOGRAM ON ADMISSION IN PATIENTS WITH UNSTABLE ANGINA

Reversible electrocardiographic changes (ST segment depression or elevation $\geqslant 0.01 \mathrm{mV}$ or $\mathrm{T}$ wave inversion, or both) were found at admission in six $(46 \%)$ of 13 patients with UA $(-)$ and in seven $(88 \%)$ of eight patients with UA $(+)$. The difference was not statistically significant $(p=0 \cdot 27)$.

CREATINE KINASE MB AND ST SEGMENT CHANGES IN PATIENTS WITH UNSTABLE ANGINA

Twenty of the 21 patients with unstable angina had ST segment analysis by Holter monitoring during the first 24 hours after admission. There were episodes of significant ST segment depression in six of 12 patients with UA $(-)$ but in all patients with UA $(+)$. There was a significant association between the presence of reversible ST segment depression and serum enzyme fluctuation ( $p<0.05$ ).

\section{CREATINE KINASE MB AND IN-HOSPITAL} CLINICAL OUTCOME

The presence of ischaemic heart disease was confirmed by either an exercise test or coronary angiography in all patients with unstable angina. No patients with unstable angina without enzyme changes had coronary events during their hospital stay. Two patients with unstable angina and enzyme changes later had an acute myocardial infarction during their hospital stay.

\section{Discussion}

The results of the present study indicate that the new creatine kinase MB immunoassay is a promising diagnostic tool because it may help to determine the frequency and severity of myocardial ischaemic events in the different coronary syndromes. Until now assessment of damage to the ischaemic myocardium by measurement of creatine kinase isoenzymes has mainly been based upon analysis of creatine kinase $\mathbf{B}$ by immunochemical methods or creatine kinase $\mathrm{MB}$ by electrophoretic or chromatographic methods. ${ }^{12-14}$ These methods are satisfactory for diagnosing acute myocardial infarction but they are less sensitive for monitoring continuing myocardial ischaemia. Creatine kinase MB specific enzyme linked immunoadsorbent assays have a high sensitivity. ${ }^{15-18}$ This method has been further improved by using a double antibody technique, which gives a highly specific and sen- sitive assay with a very low limit of detectability. ${ }^{10}$

In the present study the group without ischaemic heart disease represents the background serum concentration of creatine kinase $\mathrm{MB}$ and the group with acute myocardial infarction the full extent of enzyme concentration when there is irreversible cell damage. So these two patient groups are ideal reference groups for the study of serum enzyme concentration in patients with angina pectoris.

Despite the fact that ischaemia of short duration, verified electrocardiographically, was induced by exercise serum creatine kinase MB concentrations in the group with stable angina resembled those in the group without ischaemic heart disease. This indicates no enzyme leakage after a transient ischaemic attack in patients with chronic stable angina. Similar results have been reported by others. ${ }^{6}{ }^{19}$

In the group with unstable angina, however, our results indicate that the grade of unstable angina may reflect the degree of myocardial damage. Some of the patients with unstable angina showed clear evidence of ischaemic injury-serial changes and higher mean values of serum creatine kinase $\mathrm{MB}$ concentrationafter the onset of symptoms than a reference group of patients without ischaemic heart disease or with stable angina. In addition, fluctuations in creatine kinase $\mathrm{MB}$ correlated with evidence of repetitive ischaemic episodes on continuous ST segment monitoring during the first 24 hours after admission.

Whether enzyme release is due to minor necrosis of myocardial tissue or severe but reversible ischaemic injury cannot be determined from the present study. Enzyme leakage has been found under experimental conditions in ischaemically damaged myocardial tissue without signs of irreversible myocardial injury. ${ }^{2021}$ On the other hand, studies of patients suggested that slight increases in serum concentrations of creatine kinase and creatine kinase $B$ were caused by micronecroses. ${ }^{22}$ This is supported by techniques such as myocardial scintigraphy with technetium-99m-pyrophosphate and necropsy studies. ${ }^{23} 24$

In patients with unstable angina serum creatine kinase MB concentrations were only slightly raised and the time course of the increase in creatine kinase $M B$ resembled the curves obtained from patients with acute myocardial infarction. This suggests that patients with unstable angina had minimal myocardial necrosis. The earlier rise in peak creatine kinase $M B$ in unstable angina resembled the enzyme course described in patients with non-Q wave infarction and has led to the hypothesis that reperfusion is likely to occur in patients with non- $Q$ wave acute myocardial infarction. ${ }^{25}$ Reperfusion is also likely to occur after transient non-perfusion in unstable angina. However, the UA $(+)$ patients did not have acute myoćardial ischaemia by the classic World Health Organisation criteria. ${ }^{9}$ Findings were similar when serum myoglobin was used as a marker of myocardial ischaemia in a group of patients with an acute ischaemic myocardial insult. ${ }^{26}$ Therefore the gradation of patients with unstable angina implies the identification of a subgroup with small size myocardial 
necrosis. The various time courses of creatine kinase MB within this population (fig 2) further indicate that this enzymatic marker of myocardial ischaemia need not be restricted to conventional myocardial infarction. It also reflects-in time and degree-the range of ischaemic damage of myocardial tissue. In this context the present results confirm that myocardial infarction and enzyme release are not all-or-non processes, but rather a continuum dependent on the duration and intensity of ischaemia and on the condition of the myocardium at the onset of the ischaemic episode..$^{26-28}$

The subgrouping of patients in a study of this type is crucial. Unstable angina was diagnosed on clinical grounds and acute myocardial infarction was excluded by conventional enzymatic methods and electrocardiographic findings. Though the term unstable angina includes a wide range of patients with ischaemic heart disease the term has been clinically defined. To improve the understanding of this complex clinical entity, Braunwald recently proposed a clinical classification of unstable angina. ${ }^{29}$ This classification is based on the severity of angina-new onset of severe angina or accelerated angina, angina at rest within the past month but not within the preceding 48 hours, and angina at rest within 48 hours. These three grades of severity are classified further on the basis of the development of angina in the presence of extracardiac conditions that intensify myocardial ischaemia, develop in the absence of extracardiac conditions, or develop within two weeks after acute myocardial infarction. According to this classification all patients with unstable angina in the present study had primary unstable angina (group IIIB) because they presented with angina within 48 hours in the absence of extracardiac conditions. Half of a similarly defined group of patients with unstable angina had raised concentrations of serum myoglobin. ${ }^{26}$ This accords with our finding raised concentrations of serum creatine kinase $\mathrm{MB}$ in $38 \%$ of the patients.

Coronary events occurred only in the patients with unstable angina who also had raised serum creatine kinase $M B$. This increase in serum creatine kinase $M B$ may be an additional prognostic factor in patients with unstable angina. This point adds further support to the view that patients with unstable angina and raised creatine kinase $\mathrm{MB}$ activity have areas of myocardial necrosis.

The highly sensitive creatine kinase $\mathrm{MB}$ immunoassay is a promising means of extending our knowledge of the severity of myocardial ischaemic events in the different coronary syndromes. Application of the method is not restricted to conventional myocardial infarction. It is able to reflect-in time and degreethe range of ischaemic damage in myocardial tissue. The different time courses of creatine kinase $M B$ in various patient groups in the present study show that the acute ischaemic syndrome-comprising unstable angina, acute myocardial infarction, and sudden ischaemic death-represents a continuum of ischaemic myocardial damage. It is tempting to suggest that the difference between no enzyme release and minimal enzyme release reflects a separation between stable and dynamic ischaemic conditions; if so the "dividing line" would fall within unstable angina.

1 DeWood MA, Spores J, Notske R, et al. Prevalence of tota coronary occlusion during the early hours of transmura infarction. N Engl J Med 1980;303:897-901.

2 Breshnahan DR, Davies JL, Hohnes DR, et al. Angiographic occurrence and clinical correlates of intraluminal coronary artery thrombosis. Role of unstable angina. $J A m$ Coll Cardiol 1985;2:285-9.

3 Fuster V, Steele PM, Chesebro JH. Role of platelets and thrombosis in coronary arteriosclerotic disease and sudden death. J Am Coll Cardiol 1985;5:175B-83B.

4 Falk E. Unstable angina with fatal outcome: dynamic coronary occlusion leading to infarction and/or sudden death. Circulation 1985;71:699-708.

5 Epstein SE, Palmeri ST. Mechanisms contributing to precipitation of unstable angina and acute myocardial precipitation of unstable angina and acu

6 Thygesen $K$, Horder M, Kroll L, Hyltoft Petersen P Haghfelt T. Creatine kinase and creatine kinase B-subunit in stable and unstable angina pectoris. Eur J Clin Invest 1986;16:1-4

7 Hoberg E, Katus HA, Diederich KW, Kübler W. Myoglobin, creatine kinase-B isoenzyme, and myoglobin light chain release in patients with unstable angina pectoris. Eur Heart $J$ 1987;8:989-94.

8 Bashour TT, Myler RK, Andreae GE, Stertzer SH, Clark DA, Ryan CJM. Current concepts in unstable myocardial ischemia. Am Heart J 1988;115:850-61.

9 World Health Organization. Report of the fifth working group on the establishment of ischaemic heart disease registers.

.

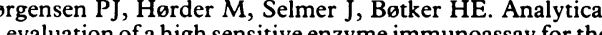
evaluation of a high sensitive enzyme immunoassay for the Chem 1990;36:1502-5.

11 Gerhardt W, Waldenstrøm J, Horder M, et al. Creatine kinase and creatine kinase B-subunit activity in serum in cases of suspected myocardial infarction. Clin Chem 1982, 28:277-83

12 Wagner GS, Roe CR, Limbird LE, Rosati RA, Wallace AG. The importance of the identification of the myocardialspecific isoenzyme of creatine phosphokinase (MB form) in the diagnosis of acute myocardial infarction. Circulation 1973;47:263-9.

13 Smith AF, Radford D, Wong CP, Oliver MF. Creatine kinase MB isoenzyme studies in diagnosis of myocardial infarction. Br Heart J 1976;38:224-32.

14 Grande P, Christiansen C, Pedersen A, Christensen MS Optimal diagnosis in acute myocardial infarction. A costeffectiveness study. Circulation 1980;61:723-32.

15 Chan DW, Taylor E, Frye R, Blitzer R-L. Immunoenzymatic assay for creatine kinase MB with subunit specific monoclonal antibodies compared with an immunochemical method and electrophoresis. Clin Chem 1985;31: 723-8.

16 Koch TR, Metha VJ, Nipper HC. Clinical and analytical evaluation of kits for measurement of creatine kinase isoenzyme MB. Clin Chem 1986;32:186-91.

17 Murthy VV, Karman A. Activity concentration and mass concentration (monoclonal antibody immunoenzymatic method) compared for creatine kinase $M B$ isoenzyme in serum. Clin Chem 1986;32:1956-9.

18 Gorus F, Claessens V, Goubert P, Laurups M. A sensitive bioluminiscent immunoinhibition test for $\mathrm{CK}-\mathrm{B}$ subunit activity and CK-MB specific ELISA compared: correlation with agarose electrophoresis and influence of $\mathrm{CK}$ isoenzyme profile on results. Clin Chem 1988;34:1474-8.

19 Bagger JP, Ingerslev J, Heinsvig EM. Creatine kinase and creatine kinase subunit-B in coronary sinus blood in pacing induced angina pectoris. Scand J Clin Lab Invest 1982;42:617-20.

20 Piper HM, Schwartz P, Spahr R, Hutter SF, Spieckerman PG. Early enzyme release from myocardial cells is not due PG. Early enzyme release from myocardial cells is not due to irreversi

21 Heyndrickx GR, Amano J, Kenna T, et al. Creatine kinase release not associated with myocardial necrosis of short periods of coronary artery occlusion in conscious baboons. J Am Coll Cardiol 1985;6:1299-303.

22 Katus HA, Diederich KW, Hoberg E, Kübler W. Circulating cardiac myosin light chains in patients with angin at rest: identification of a high risk subgroup. $\mathrm{J} \mathrm{Am} \mathrm{Coll}$ Cardiol 1988;11:487-93.

23 Lessem J, Johansen BW, Nosslin B, Thorell J. Myocardia scintigraphy with $99 \mathrm{~m}$-Tc-pyrophosphate in patients with unstable angina pectoris. Acta Med Scand 1978;203: 491-5.

24 Robbins SL. Clinicopathological correlations in coronary atherosclerosis. Four hundred and thirty patients studied with postmortem coronary angiography. Circulation 1963 27:170-84.

25 Fuster V, Badimon L, Cohen M, Ambrose JA, Badimon JJ, Chesebro J. Insights into the pathogenesis of acute ischemic syndromes. Circulation 1988;77:1213-20.

26 Isakov A, Shapira I, Burke M, Almong C. Serum myoglobin sakov A, Shapira I, Burke M, Almong C. Serum myoglobin
levels in patients with ischemic myocardial insult. Arch levels in patients with ischem.
Intern Med 1988;148:1762-5.

27 Kristensen SR, Hørder M. Biochemical mechanisms in enzyme release. Adv Clin Enzymol 1988;6:87-94.

28 Braunwald E, Kloner RA. The stunned myocardium: prolonged, postischemic ventricular dysfunction. Circulation longed, postischemi

29 Braunwald E. Unstable angina. A classification. Circulation 1989;80:410-4 